\title{
Distribution Law of Three Spontaneous Combustion Zones in the Goaf Area of a Fully Mechanized Working Face under High Ground Temperature
}

\author{
Duolei Kuai \\ Zhujixi Coal Mine, Wanbei Coal-Electricity Group Co. Ltd., Huainan 232082, China
}

Corresponding Author Email: kd11933@163.com

https://doi.org/10.18280/eesrj.080204

Received: 18 February 2021

Accepted: 1 May 2021

\section{Keywords:}

high ground temperature, goaf, three spontaneous combustion zones, numerical simulation, field measurement

\begin{abstract}
To figure out the distribution law of three spontaneous combustion zones in the goaf area of fully mechanized working face under high ground temperature, this study took the 11501\# fully mechanized mining face of Zhujixi Coal Mine as the research object, and employed software Fluent to perform numerical simulations on the $\mathrm{O}_{2}$ concentration distribution in the goaf; then, combining with the actual situations on the site, the highlocation boreholes and grout holes of the roof gas drainage roadway of the 11501\# working face were selected as measuring points to measure the $\mathrm{O}_{2}$ concentration changes in a few positions such as in middle part of the goaf, on the air intake side, and on the air return side. The results show that, the numerical simulation results were basically consistent with the field measurement results, in the middle part of the goaf, the scope of the oxidation zone was $26.4 \mathrm{~m}-62 \mathrm{~m}$; on the air intake side, the scope of the oxidation zone was $32 \mathrm{~m}-96 \mathrm{~m}$; on the air return side, the scope of the oxidation zone was $28.4 \mathrm{~m}-91 \mathrm{~m}$. The research findings of this paper provided a scientific reference for formulating fireprevention and fire-extinguishing technical plans for mines.
\end{abstract}

\section{INTRODUCTION}

Coal spontaneous combustion is one of the main natural disasters in coal mines, which seriously threatens the safety of mine production [1-3]. Statistics show that among the large and medium-sized coal mines in China, mines with serious or very serious spontaneous combustion hazards account for $72.86 \%$. According to the results of a field survey on more than 130 large and medium-sized mines in 25 major coalproducing provinces and regions in China, mines with a shortest spontaneous combustion period within 3 months account for more than $50 \%$ [4]. The spontaneous combustion of coal is also one of the main causes of coal dust and gas explosions. According to incomplete statistics, in the recent ten years, there have been 11 gas explosion accidents caused by spontaneous combustion of coal in China, resulting in 455 deaths.

Zhujixi Coal Mine is a mine with high ground pressure and high ground temperature. Mining under high ground pressure would increase the degree of coal fragmentation, thereby improving the oxidation and heat accumulation conditions [57]. The high ground temperature environment would inhibit convection heat loss and heat transfer of the coal, and improve the heat accumulation environment; at the same time, the high ground temperature increases the free radical activity of the coal, the oxidizability of the coal increases accordingly, and thus the risk of spontaneous combustion increases as well [810]. In order to study the distribution law of the three spontaneous combustion zones in the goaf area under the conditions of high ground pressure and temperature, world field scholars have carried out a lot of research, for example, through on-site observation, scholar Cheng Weimin analyzed the change laws of temperature, $\mathrm{CO}$ and $\mathrm{O}_{2}$ concentration in the goaf, and determined the scopes of the three spontaneous combustion zones according to the length of the oxidation and heat accumulation zone in the goaf $[11,12]$. Scholar Zhang Xinhai established a mathematical model of seepage, oxidation, and diffusion in the goaf under drainage conditions, then he used numerical simulation to solve the model and obtained the change laws of $\mathrm{O}_{2}$ concentration and air leakage intensity in the goaf under drainage conditions [13]. Their findings contributed a lot to the research on the three spontaneous combustion zones in the goaf, but they haven't concerned the three spontaneous combustion zones in the goaf in high ground temperature environment. Therefore, this paper takes the 11501\# working face of Zhujixi Coal Mine as the research object to explore the distribution law of the three spontaneous combustion zones in the goaf under complex high ground temperature conditions, in the hopes of providing a useful reference for formulating fire-prevention and fireextinguishing technical plans for mines.

\section{DIVISION CRITERIA AND ANALYSIS OF THREE SPONTANEOUS COMBUSTION ZONES}

The three spontaneous combustion zones are the heat dissipation zone, the self-ignition zone, and the suffocation zone [14-16]. As the working face of the mine is advancing, the roof of the coal seam gradually falls, forming a loose caving zone within a certain range. In this area, the heat generated by the oxidation and self-ignition of the leftover coal is mostly taken away by the air leakage, so the heat is not accumulated easily here and it won't self-ignite, and this area is called the heat dissipation zone. Then, as it goes deeper into the goaf, the air leakage becomes less and is not enough to take 
away the heat generated by the oxidation of the leftover coal, the heat accumulates and the oxidation of the leftover coal accelerates, which would eventually lead to the self-ignition of the leftover coal, and this area is called the self-ignition zone. Further, in area deeper than the self-ignition zone, the speed of air leakage is smaller and the $\mathrm{O}_{2}$ concentration is lower, which cannot support the oxidation reaction of the leftover coal, the leftover coal in this area does not have the conditions for spontaneous combustion, and this area is called the suffocation zone $[17,18]$.

Coal oxidation and spontaneous combustion must meet three conditions at the same time: (1) The coal has a tendency of self-ignition and is accumulated in a broken state; (2) Continuous ventilation and oxygen supply conditions; (3) Continuous heat accumulation environment, and sufficient time for oxidation. In mine goaf area with coal spontaneous combustion tendency, the volume of air leakage directly affects the oxygen supply and heat accumulation conditions of the coal, and the $\mathrm{O}_{2}$ concentration directly determines the oxidizability of the coal seam [19-21]. Therefore, the division of the three spontaneous combustion zones in the goaf area is based on three criteria: air leakage speed, temperature distribution, and $\mathrm{O}_{2}$ concentration $[22,23]$. Among the three, the air leakage speed is a vector, which is difficult to measure; temperature is the most direct indicator reflecting the degree of spontaneous combustion of the coal, but since the coal is a poor conductor and the heat transfer process in the goaf is very complicated, the temperature changes in each zone of the goaf can hardly be measured; $\mathrm{O}_{2}$ concentration is not only related to the air leakage state, but also related to the degree of oxidation of the leftover coal, in areas of higher degree of spontaneous combustion, the $\mathrm{O}_{2}$ consumption is higher and the $\mathrm{O}_{2}$ concentration is lower, the $\mathrm{O}_{2}$ content directly reflects the oxidation and heat accumulation conditions of the leftover coal $[24,25]$. Therefore, the scope of the three spontaneous combustion zones can be determined according to the distribution of $\mathrm{O}_{2}$ concentration in the goaf; moreover, $\mathrm{O}_{2}$ concentration is a scalar quantity, which is easy to measure on the site. In summary, the Zhujixi Coal Mine used $\mathrm{O}_{2}$ concentration to divide the three spontaneous combustion zones in the goaf.

It is generally believed that the criteria for dividing the three spontaneous combustion zones based on $\mathrm{O}_{2}$ concentration are: $\mathrm{O}_{2}$ concentration of heat dissipation zone > $18 \% ; \mathrm{O}_{2}$ concentration of self-ignition zone is $8 \%-18 \% ; \quad \mathrm{O}_{2}$ concentration of suffocation zone $<8 \%$ [26].

\section{NUMERICAL SIMULATION OF THE DISTRIBUTION LAW OF $\mathrm{O}_{2}$ CONCENTRATION IN THE GOAF}

To figure out the accurate oxidation process of leftover coal in the goaf, a goaf $\mathrm{O}_{2}$ concentration distribution law mathematical model was constructed to determine key parameters such as the permeability, $\mathrm{O}_{2}$ consumption, and diffusion coefficient of the goaf area, and the CFD software was employed to simulate the $\mathrm{O}_{2}$ concentration distribution law in the goaf.

\subsection{Boundary conditions of the goaf model}

(1) The air pressures at the intake airway and return airway were set as inlet pressure and outlet pressure, the pressure difference was $300 \mathrm{~Pa}$, that is, the air pressure at the intake airway was $300 \mathrm{~Pa}$, and the air pressure at the return airway was $0 \mathrm{~Pa}$, the temperature was $300 \mathrm{~K}$, and the air density was $1.293 \mathrm{~kg} / \mathrm{m}^{3}$.

(2) In the construction of roof gas drainage roadway, the drainage pressure of high-location boreholes was $-6 \mathrm{kPa}$.

(3) In the goaf model, the upper and lower surfaces and the surrounding boundary conditions were set as Wall boundaries.

(4) The air in the roadways was compressible ideal gas, and the seepage process was regarded as a stable isothermal flow process.

(5) The air flow in the goaf conformed to the Darcy's law.

(6) The multi-medium in the goaf was regarded to be isotropic.

\subsection{Determination of model parameters}

According to FICK's law, the diffusion equation of various gases in the goaf is as follows:

$$
J_{i}=\rho D_{m} \frac{\partial X_{i}}{\partial x_{i}}-\frac{D \frac{T}{i}}{T} \frac{\partial T}{\partial x_{i}}
$$

where, $J_{i}$ is the diffusion flow of the $i$-th gas, which is mainly caused by the concentration gradient and heat gradient; $\rho$ is the density of the mixed gas in the goaf; $D_{m}$ is the diffusion coefficient of the mixed gas; $X_{i}$ is the mass fraction of the $i$-th gas; $x_{i}$ is the distance parameter; $D_{\frac{T}{i}}^{T}$ is the heat diffusion coefficient; $T$ is temperature.

For non-rarefied gases, Formula (1) can be replaced by the form of multi-component diffusion, namely:

$$
J_{i}=\rho \frac{M_{i}}{M_{m i x}} \sum_{j, j \neq i} D_{i j}\left(\frac{\partial X_{j}}{\partial x_{i}}+\frac{X_{j}}{M_{m i x}} \frac{\partial M_{m i x}}{\partial x_{i}}\right)-\frac{D \frac{T}{i}}{T} \frac{\partial T}{\partial x_{i}}
$$

where, $M_{i}$ is the relative molecular weight of gas $i ; M_{m i x}$ is the relative molecular weight of the mixed gas; $D_{i j}$ is the multicomponent diffusion coefficient of component $i$ in gas $j$.

The physical adsorption, chemical adsorption, and coaloxygen recombination processes between oxygen and leftover coal are the main reasons for the continuous decrease in $\mathrm{O}_{2}$ concentration in the goaf. The $\mathrm{O}_{2}$ consumption rate in the lowtemperature oxidation stage is:

$$
R o_{2}=A V_{O_{2}}{ }^{n} \exp (-E / R T)
$$

where, $E$ is the activation energy of the reaction, its value varies between $12-95 \mathrm{~kJ} / \mathrm{mol}$ according to the different coal types, in this experiment, its value takes $62 \mathrm{~kJ} / \mathrm{mol} ; A$ is the pre-exponential factor, which depends on the coal rank and the test method; $n$ is a constant, its value is between $0.5-1.0 ; R$ is the gas constant; $R_{O 2}$ is the volume fraction of $\mathrm{O}_{2}$.

\subsection{Determination of danger zone in the goaf}

The physical parameters of the $11501 \#$ fully mechanized mining face are as follows: the strike direction length of the goaf was $145 \mathrm{~m}$, the dip direction length of the goaf was $220 \mathrm{~m}$, the roadway section was $5.2 \mathrm{~m} \times 4 \mathrm{~m}$, the working face section was $7.2 \mathrm{~m} \times 2 \mathrm{~m}$, the model height was $50 \mathrm{~m}$, the coal seams extended in the horizontal direction and were upward mined at $2 \sim 9^{\circ}$, U-shaped ventilation mode was adopted, and the air 
volume distribution of the working face was $1670 \mathrm{~m}^{3} / \mathrm{min}$.

\subsection{Numerical simulation results}

Based on above parameters, the Fluent software was employed to perform numerical simulations on the $\mathrm{O}_{2}$ concentration in the goaf, and the results are shown in Figure 1. The $\mathrm{O}_{2}$ concentration in the middle of the goaf decreased with the increase of the distance from the working face. When the distance from the working surface was $26.2 \mathrm{~m}$, the $\mathrm{O}_{2}$ concentration dropped to $18 \%$; when the distance from the working surface reached $62.5 \mathrm{~m}$, the $\mathrm{O}_{2}$ concentration dropped to $8 \%$. The air leakage on the air intake side was stronger, the decline trend of $\mathrm{O}_{2}$ concentration was slower, when the distance from the working face was $31.5 \mathrm{~m}$, the $\mathrm{O}_{2}$ concentration dropped to $18 \%$; when the distance from the working face was $96.2 \mathrm{~m}$, the $\mathrm{O}_{2}$ concentration dropped to $8 \%$, and it entered the suffocation zone. As for the air return side, under the impact of the drainage of high-location boreholes, the air leakage was stronger, the decline trend of $\mathrm{O}_{2}$ concentration was slower, when the distance from the working face was $28.2 \mathrm{~m}$, the $\mathrm{O}_{2}$ concentration dropped to $18 \%$; when the distance from the working face was $90.6 \mathrm{~m}$, the $\mathrm{O}_{2}$ concentration dropped to $8 \%$, and it entered the suffocation zone.

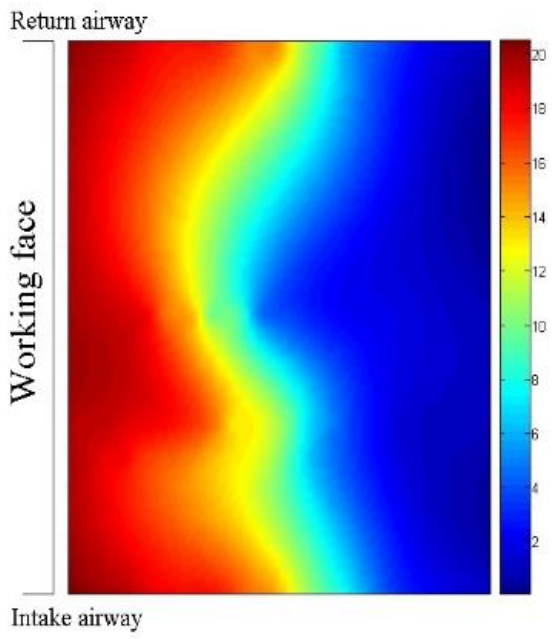

(a) Cloud map of $\mathrm{O}_{2}$ concentration in the goaf

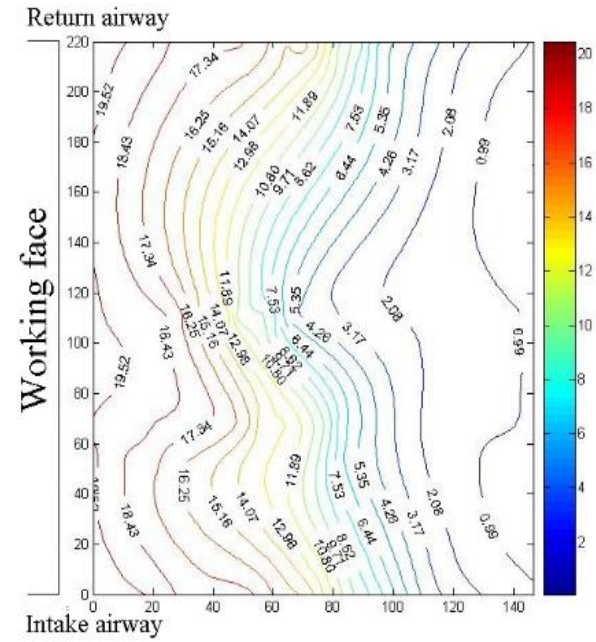

(b) Contour map of $\mathrm{O}_{2}$ concentration in the goaf

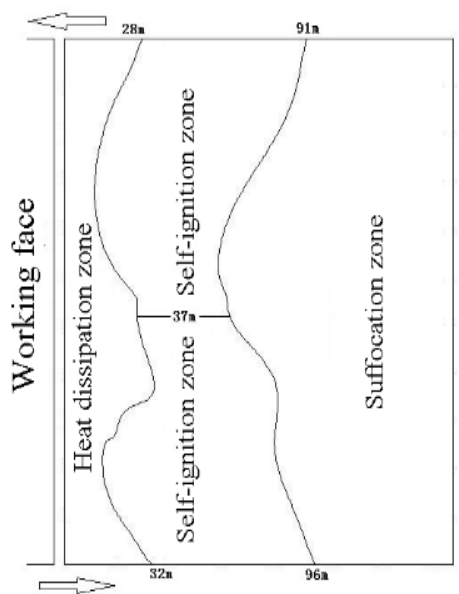

(c) Scopes of three spontaneous combustion zones in the goaf

Figure 1. Cloud and contour maps of $\mathrm{O}_{2}$ concentration in the goaf and the scopes of three spontaneous combustion zones

\section{FIELD MEASUREMENT}

\subsection{Overview of the working face}

Zhujixi Coal Mine is a coal and gas outburst mine. The 11. ${ }_{2}$ coal seam was first mined as the lower protective layer of the $13_{-1}$ coal. The $11_{-2}$ coal that was mined first was identified as an outburst coal seam with a maximum original gas pressure of $1.2 \mathrm{MPa}$ and a maximum original gas content of $8.63 \mathrm{~m}^{3} / \mathrm{t}$, its shortest spontaneous ignition period is 45 days, and it belongs to the Type II spontaneous combustion coal seam, the coal dust has the risk of explosion.

The 11501\# working face that was first mined is located in the 5-th mining area of the $11_{-2}$ coal, which has the characteristics of deep burial and high ground temperature, the burial depth of the coal seam is $744.17-1108.88 \mathrm{~m}$, and the surrounding rock temperature is $35.44-46.56^{\circ} \mathrm{C}$. In the working face, the occurrence of coal seam is stable with an average thickness of $1.59 \mathrm{~m}$. The working face is $220 \mathrm{~m}$ wide, the stoping length is $1480 \mathrm{~m}$, and the roof gas drainage roadway is $64.2 \mathrm{~m}$ staggered along the track roadway of the working face. At $1.8-8.7 \mathrm{~m}$ in the upper part of the $11_{-2}$ coal seam of the working face is the $11_{-3}$ coal, the thickness of the $11_{-3}$ coal seam is $0.35 \mathrm{~m}$, it falls into the goaf area with the stoping of the working face, and the $11_{-2}$ coal that has not been fully stoped when the working face crosses the fault becomes the leftover coal, which has increased the leftover coal in the goaf. At the same time, the gas drainage increases the air leakage of the goaf, creating conditions for the spontaneous combustion of leftover coal in the goaf.

\subsection{Layout of measuring points}

Making use of the high-location boreholes and the grout holes of the roof gas drainage roadway of the 11501\# working face, four measuring points were arranged near the positions of the intake airway, the middle part of the goaf, and the return airway to observe the change laws of $\mathrm{O}_{2}$ concentration in the goaf, the layout of the measuring points is shown in Figure 2.

When the measuring points entered the goaf area, the measurement started and the gas composition was analyzed by a gas chromatograph. After analyzing the data, the change curves of $\mathrm{O}_{2}$ concentration in the goaf with the advancing distance of the working face were plotted, as shown in Figure 3 .

According to Figure 3, the $\mathrm{O}_{2}$ concentration in the middle part of the goaf of the $11501 \#$ mining face decreased rapidly with the advancement of the working face. When the depth of the goaf reached $26.4 \mathrm{~m}, \mathrm{O}_{2}$ concentration dropped to $18 \%$, and when the depth of the goaf reached $62 \mathrm{~m}, \mathrm{O}_{2}$ concentration dropped to $8 \%$, and it entered the suffocation zone. The air leakage on the air intake side was stronger, the $\mathrm{O}_{2}$ concentration decreased slowly, when the depth of the goaf reached $32 \mathrm{~m}, \mathrm{O}_{2}$ concentration dropped to $18 \%$, when the depth of the goaf reached $96 \mathrm{~m}, \mathrm{O}_{2}$ concentration dropped to $8 \%$ and it entered the suffocation zone. On the air return side, 
under the impact of the drainage of high-location boreholes, the air leakage was stronger, the $\mathrm{O}_{2}$ concentration decreased slowly, when the depth of the goaf reached $28.4 \mathrm{~m}, \mathrm{O}_{2}$ concentration dropped to $18 \%$, when the depth of the goaf reached $91 \mathrm{~m}, \mathrm{O}_{2}$ concentration dropped to $8 \%$ and it entered the suffocation zone.

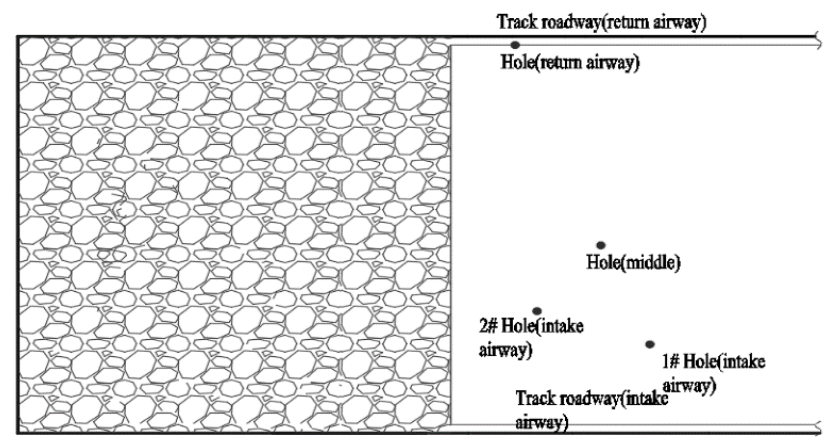

Figure 2. Layout of measuring points

Based on the simulation results, the field measurement results of $\mathrm{O}_{2}$ concentration, and the division criteria, the scopes of the three spontaneous combustion zones in the goaf of the $11501 \#$ fully mechanized mining face were obtained, as listed in Table 1.

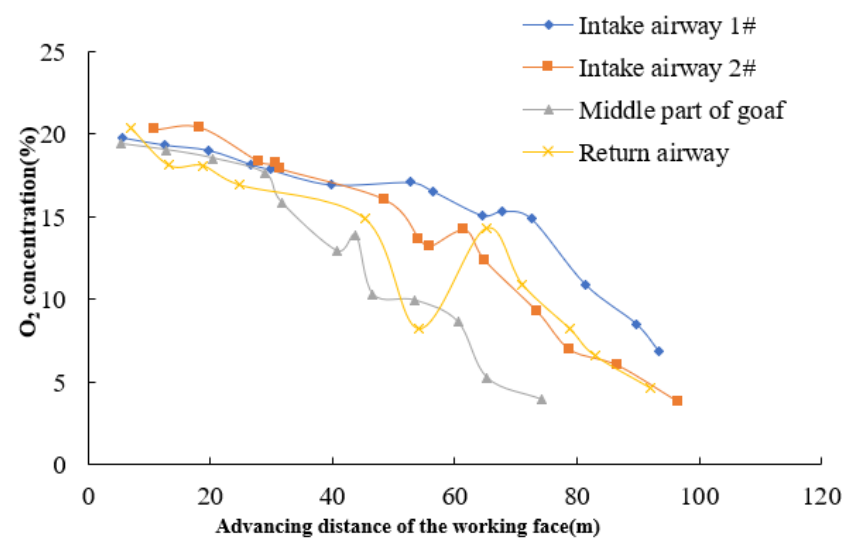

Figure 3. Change curves of $\mathrm{O}_{2}$ concentration in the goaf with the advancing distance of the working face

Table 1. Scopes of the three spontaneous combustion zones in the goaf divided based on $\mathrm{O}_{2}$ concentration

\begin{tabular}{cccc}
\hline Position & $\begin{array}{c}\text { Scope of the } \\
\text { heat dissipation } \\
\text { zone } \\
\text { (m) }\end{array}$ & $\begin{array}{c}\text { Scope of the } \\
\text { self-ignition } \\
\text { zone } \\
\text { (m) }\end{array}$ & $\begin{array}{c}\text { Scope of the } \\
\text { suffocation } \\
\text { zone } \\
\text { (m) }\end{array}$ \\
\hline $\begin{array}{c}\text { On the air intake } \\
\text { side }\end{array}$ & $<32$ & $32-96$ & $>96$ \\
$\begin{array}{c}\text { In the middle of } \\
\text { the goaf }\end{array}$ & $<26.4$ & $26.4-62$ & $>62$ \\
$\begin{array}{c}\text { On the air return } \\
\text { side }\end{array}$ & $<28.4$ & $28.4-91$ & $>91$ \\
\hline
\end{tabular}

\section{CONCLUSIONS}

(1) According to the actual conditions of the 11501 \# fully mechanized mining face, the Fluent software was employed to perform numerical simulations on the $\mathrm{O}_{2}$ concentration in the goaf area. The results showed that, in the middle part of the goaf, when the distance from the working face was $26.2 \mathrm{~m}$, the $\mathrm{O}_{2}$ concentration dropped to $18 \%$; when the distance from the working face reached $62.5 \mathrm{~m}$, the $\mathrm{O}_{2}$ concentration dropped to $8 \%$. On the air intake side, when the distance from the working surface was $31.5 \mathrm{~m}$, the $\mathrm{O}_{2}$ concentration dropped to $18 \%$; when the distance from the working surface was $96.2 \mathrm{~m}$, the $\mathrm{O}_{2}$ concentration dropped to $8 \%$. On the air return side, when the distance from the working surface was $28.2 \mathrm{~m}$, the $\mathrm{O}_{2}$ concentration dropped to $18 \%$; when the distance from the working surface was $90.6 \mathrm{~m}$, the $\mathrm{O}_{2}$ concentration dropped to $8 \%$.

(2) A few measuring points were arranged on site to measure the $\mathrm{O}_{2}$ concentration in the goaf area of the 11501 \# working face, and the obtained results showed that, in the middle part of the goaf, when the depth of the goaf was $26.4 \mathrm{~m}$, the $\mathrm{O}_{2}$ concentration dropped to $18 \%$; when the depth of the goaf was $62 \mathrm{~m}$, the $\mathrm{O}_{2}$ concentration dropped to $8 \%$. On the air intake side, when the depth of the goaf reached $32 \mathrm{~m}$, the $\mathrm{O}_{2}$ concentration dropped to $18 \%$; when the depth of the goaf reached $96 \mathrm{~m}$, the $\mathrm{O}_{2}$ concentration dropped to $8 \%$. On the air return side, when the depth of the goaf reached $28.4 \mathrm{~m}$, the $\mathrm{O}_{2}$ concentration dropped to $18 \%$; when the depth of the goaf reached $91 \mathrm{~m}$, it dropped to $8 \%$.

(3) The numerical simulation results and the field measurement results were basically the same. The scope of the oxidation zone in the goaf area was $26.4 \mathrm{~m}-62 \mathrm{~m}$; on the air intake side, its scope was $32 \mathrm{~m}-96 \mathrm{~m}$; on the air return side, its scope was $28.4 \mathrm{~m}-91 \mathrm{~m}$.

\section{REFERENCES}

[1] Chen, X., Li, L., Guo, Z., Chang, T. (2019). Evolution characteristics of spontaneous combustion in three zones of the goaf when using the cutting roof and release pressure technique. Energy Science \& Engineering, 7(3): 710-720. https://doi.org/10.1002/ese3.287

[2] Zhuo, H., Qin, B., Qin, Q. (2021). The impact of surface air leakage on coal spontaneous combustion hazardous zone in gob of shallow coal seams: A case study of Bulianta Mine, China. Fuel, 295: 120636. https://doi.org/10.1016/j.fuel.2021.120636

[3] Hao, M., Li, Y., Song, X., Kang, J., Su, H., Zhou, F. (2019). Hazardous areas determination of coal spontaneous combustion in shallow-buried gobs of coal seam group: A physical simulation experimental study. Environmental Earth Sciences, 78(1): 39. https://doi.org/10.1007/s12665-018-8010-5

[4] Zhai, X., Wang, T., Li, H., Wang, K., Zubíček, V. (2019). Determination and predication on three zones of coal spontaneous combustion at fully-mechanised working face with nitrogen injection. International Journal of Oil, Gas and Coal Technology, 22(3): 389-416. https://doi.org/10.1504/IJOGCT.2019.103068

[5] Wen, H., Guo, J., Jin, Y., Wang, K., Zhang, Y., Zheng, $X$. (2017). Experimental study on the influence of different oxygen concentrations on coal spontaneous combustion characteristic parameters. International Journal of Oil, Gas and Coal Technology, 16(2): 187-202. https://doi.org/10.1504/IJOGCT.2017.086320

[6] Pan, R.K., Li, C., Yu, M.G., Xiao, Z.J., Fu, D. (2020). Evolution patterns of coal micro-structure in environments with different temperatures and oxygen conditions. $\quad$ Fuel, 261: 116425. 
https://doi.org/10.1016/j.fuel.2019.116425

[7] Chen, L., Yang, J., Ding, P. (2020). Dynamic evolution of negative pressure impact of cross-cut on oxygen concentration field in coal mine Goaf. Heat and Mass Transfer, 1-13. https://doi.org/10.1007/s00231-02002981-z

[8] Ma, L., Ren, L.F., Wang, N.G., Han, L. (2016). Study on characteristics of coal spontaneous combustion and precontrol methods in deep mine high ground temperature working face. Coal Science and Technology, 44(10): 3943.

[9] Yang, S., Kan, X., Wang, X. (2021). Study on the application of comprehensive treatment technology for fire prevention and extinguishing in deep well and high ground temperature island working face. Energy Technology and Management, 46(2): 139-141.

[10] Huang, Z., Ma, Z., Song, S., Yang, R., Gao, Y., Zhang, Y. (2018). Study on the influence of periodic weighting on the spontaneous combustion "three-zone" in a gob. Journal of Loss Prevention in the Process Industries, 55: 480-491. https://doi.org/10.1016/j.jlp.2018.07.020

[11] Cheng, W.M., Sun, L.L., Zhang X.Q. (2012). Study on the characteristics of spontaneous combustio "three zones" in the goaf of a fully mechanized mining face based on the distribution of oxygen concentration. Mining Safety and Environmental Protection, 39(5): 7$10+99$. 4495.2012.05.002

[12] Wang, G., Cheng, W.M., Zhou G. (2010). Study on the distribution law of spontaneous combustion in goaf of fully mechanized caving face. Mining Safety and Environmental Protection, 37(1): 18-21, 90. https://doi.org/CNKI:SUN:ENER.0.2010-01-008

[13] Zhang, X.H., Wan, X., Xu, Y.H., Ding, F., Mao, W.L. (2016). Study on the "Three Zones" Law of Spontaneous Combustion in Goaf of Thick Coal Seam and Its Prevention and Control. Coal Science and Technology, 44(10): https://doi.org/10.13199/j.cnki.cst.2016.10.005

[14] Cui, Y. (2020). Study on the distribution law of spontaneous combustion "three zones" in the goaf of 10428B fully mechanized mining face in Xinzhi Coal Mine. Coal and Chemical Industry, 43(3): 91-94.

[15] Yan, B.R., Hu, X.M., Cheng, W.M., Zhao, Y.Y., Wang, W., Liang, Y.T., Liu, T.Y., Feng, Y., Xue, D. (2021). Fuel, 297:

120768 . https://doi.org/10.1016/j.fuel.2021.120768

[16] Shi, Z.F. (2019). Study on the three-dimensional distribution law of spontaneous combustion in the goaf of a fully mechanized mining face in a large mining height coal seam. Mining Safety and Environmental Protection, $\quad 46(2)$ : 47-50, 56 .
https://doi.org/CNKI:SUN:ENER.0.2019-02-011

[17] Deng, J., Lei, C., Xiao, Y., Cao, K., Ma, L., Wang, W., Laiwang, B. (2018). Determination and prediction on "three zones" of coal spontaneous combustion in a gob of fully mechanized caving face. Fuel, 211: 458-470. https://doi.org/10.1016/j.fuel.2017.09.027

[18] Deng, J., Ma, X., Zhang, Y., Xiao, Y. (2013). Quantitative determination for the" Three Zones" of coal spontaneous combustion in gobs based on probability function. Disaster Advances, 6: 210-218.

[19] Zhai, X., Wang, B., Jiang, S., Zhang, W. (2019). Oxygen distribution and air leakage law in gob of working face of U+ L ventilation system. Mathematical Problems in Engineering, https://doi.org/10.1155/2019/8356701

[20] Zhang, Y., Liu, P., Li, G., Huang, Z., Gao, Y., Zhao, B. (2013). Research on influence of injecting CO2 at goaf of 13304 caving face of Sunjiagou coal mine on its three zones of spontaneous combustion. Disaster Advances, 6: 341-349.

[21] Zhang, D., Cen, X.X., Wang, W.F., Deng, J., Wen, H., Xiao, Y., Shu, C.M. (2021). The graded warning method of coal spontaneous combustion in Tangjiahui Mine. Fuel, 288: 119635. https://doi.org/10.1016/j.fuel.2020.119635

[22] He, X.Y. (2015). Study on the distribution law of spontaneous combustion and oxidation "three zones" in the goaf of fully mechanized caving face. Shandong Coal Science and Technology, 1: 91-93. https://doi.org/10.3969/j.issn.1005-2801.2015.01.40

[23] Xie, J.N., Ni, G.H., Xie, H.C., Cheng, W.M., Zhuansun L.X. (2019). The pore characteristics of high temperature coal mine and the impact of invasive water on its development. Arabian Journal of Geosciences, 12(21): 18. https://doi.org/10.1007/s12517-019-4856-4

[24] Qin, B., Wang, H., Yang, J., Liu, L. (2016). Large-area goaf fires: A numerical method for locating hightemperature zones and assessing the effect of liquid nitrogen fire control. Environmental Earth Sciences, 75(21): 1-14. https://doi.org/10.1007/s12665-016-61735

[25] Zhuo, H., Qin, B., Qin, Q., Su, Z. (2019). Modeling and simulation of coal spontaneous combustion in a gob of shallow buried coal seams. Process Safety and Environmental Protection, 131: 246-254. https://doi.org/10.1016/j.psep.2019.09.011

[26] Yu, M., Li, J.Z., Kang, L.X., Feng, G.R., Zhang, X.L. (2014). Numerical simulation of "three zones" division of goaf based on oxygen concentration in MATLAB. Coal Mining, 19(2): 129-132. https://doi.org/10.13532/j.cnki.cn11$3677 /$ td.2014.02.036 